\title{
COMUNICACIÓN
}

\section{ANTICUERPOS CONTRA LEPTOSPIRA EN CAPIBARAS (Hydrochoerus hidrochaeris) DE UN ZOOCRIADERO DE LA AMAZONIA PERUANA}

\author{
Karina Muñoz D.', Carlos Cornejo ${ }^{2}$ y Hermelinda Rivera G $^{3}$
}

\section{Abstract}

The capybara (Hydrochoerus hidrochaeris) is the world's largest rodent and a potential protein source for humans. Scientific information is available regarding capybara biology and physiology, but little is known of its health status. Microaglutination tests detected antibodies against 14 serovars of Leptospira in serum samples from young and adult capybara males $(n=25)$ and females $(n=17)$ at a breeding facility in Iquitos, Peru. Antiboodies against 8 different serovars of Leptospira, with titers between 1:100 to I:400, were found in $71 \%(30 / 42)$ of the samples. Among the reactor animals, $26.6 \%$ had the Hardjo, Grippothyphosa and C'anicolu serovars, 20\% had Pirogenes and Holfii, $10 \%$ had Pomona, $6.6 \%$ had /cteruhemorrhagiae and $3.3 \%$ had Butaviac. No reactors were detected against the Autumnalis, Turassovi, Borincana, Javanicu, Bullum and Bratislave serovars. The presence of several Leptospira spp serovars in this capybara sample represents a potential human health risk.

Key words: Capybara (Hidrochoerus hidrochueris), Leptospira spp., antibodies

Palabras clave: Capibara (Hidrecheserus hidrochaeris), Leptespira spp, anticuerpos.

El Capibara es el roedor silvestre más grande del mundo localizado en la zona tropical desde el Canal de Panamá hasta el noroeste de Argentina, siendo conocido con diferentes nombres según el país, así se le denomina: Carpincho (Argentina), Capybara (Brasil), Chiguiro ó Chiguire (Colombia). Ronsoco (Perú) y a nivel mundial es conocido como Capibara (Gonzáles-Jiménez, 1995).

El Capibara es un buen nadador y es capaz de permanecer por un tiempo prolongado bajo el agua debido a que su mioglobina posee moléculas de arginina, de gran afinidad por el oxígeno, como suce-

\footnotetext{
'INRENA

${ }^{2}$ Biodiversidad Amuzinica (BIOAA)

'Laboratorio de Afurohiologia - FAll' - I WAS:14. Email: dl 70029 icunmmsn.edu.pe.
}

de en otros mamíferos de vida acuática (Castillo, 1986). Debido a su tamaño, productividad, rusticidad y buena adaptación al ecosistema de sabana inundable, el capibara esta siendo explotado en forma semiextensiva en varios países de América Latina para la producción de pieles de elevado precio en el mercado mundial (Gonzáles-Jiménez, 1990). Así mismo, constituye una fuente de alimento para los pobladores y campesinos del lugar.

La escasa información disponible sobre el aspecto sanitario en esta especie, indica que son animales susceptibles a muchas enfermedades infecciosas como la trypanosomiasis, dermatosis parasitaria, rabia, brucelosis y leptospirosis (Bello et al. 1974; Morales, 1978; Gonzáles-Jiménez, 1995; Piccini et al., 1971). En Maracay, Venezuela, 
se ha demostrado una alta prevalencia de Leptospira, posiblemente debido a su vida acuática, pero sin signos clínicos de leptospirosis ni lesiones histopatológicas en los aninales reactores, sugiriendo que podrían servir de reservorios de la bacteria (Jelambi, 1976).

En el Perú la crianza del Capibara es limitada a zoocriaderos pequeños y la información sobre el estado sanitario es escasa. El presente trabajo tuvo por objetivo determinar la presencia de Leptospira en Capibara de un zoocriadero en la ciudad de lquitos, departamento de Loreto, Perí. Con este propósito se obtuvieron 42 muestras de sangre de capibaras ( 25 machos y 17 hembras) entre adultos $y$ juveniles. Las muestras fueron obtenidas asépticamente de la vena femoral y el suero obtenido por coagulación y transferidos a viales y transportados a los laboratorios de la Facultad de Medicina Veterinaria de la Universidad Nacional Mayor de San Marcos.
Para la deteminación de los anticuerpos. las muestras de sueros fueron diluidas en $1: 100$ en solución salina y enfrentados a un bolumen similar de antígeno vivo de 12 serovares de Leptospira e incubados por dos horas a $28 . \mathrm{C}$. La lectura fue realizada en un microscopio de campo oscuro. La muestra fue considerada positiva a anticuerpos contra el respectivo serovar de Leptospira si el $50 \%$ o más de Leptospiras estuv ieron aglutinadas. Las muestras positivas en la dilución 1:100 a un determinado serovar, fueron diluidas hasta 1: 1600 , cada dilución enfrentada a un volumen similar de Leptospira para obtenter el titulo de anticuerpos aglutinantes.

El $71.4 \%(30 / 42)$ de las muestras presentó anticuerpos contra Leptospira siendo el serovar Hardjo el de mayor prevalencia $(26.6 \%)$ seguido por Canicola? Grippotyphosa $(20 \%)$, Wolfii y Pyrogenes $(10 \%)$ (Cuadro 1). Los titulos de anticuerpos variaron entre 1:100 a 1:400. No se deteetiron anticuerpos contra los serovares: Autumnalis, Tarassosi, Borincana, Jonamica. Ballum y Bratislava.

Cuadro 1. Distribución de los serovares de Leptospira detectados en ronsocos mediante la prueba de aglutinación microscópica.

\begin{tabular}{|c|c|c|c|}
\hline Serovar & Сера & $\begin{array}{l}\text { Número de muestras } \\
\text { con anticuerpos }\end{array}$ & ${ }^{\circ} 0$ \\
\hline lcterohemorrhagiate & RGA & 1 & 3.3 \\
\hline Butaviate & Vantienten & 1 & 3.3 \\
\hline Pomona & Pomons & 2 & 6.6 \\
\hline Wolfii & NR & 3 & 10.0 \\
\hline Grippotyphess & Moskial & 6 & 20 \\
\hline Hardjo & NR & 8 & 26.6 \\
\hline Canicola & Hond Utrech IV & 6 & 20 \\
\hline Pirogenes & Sulinem & 3 & 10.0 \\
\hline Total & & $30 / 42$ & 71.4 \\
\hline
\end{tabular}

*NR = no registrado

La lepstospirosis ha sido detectada serológicamente y por aislamiento de la baeteria en muestras provenientes del hombre. animales domésticos y salvajes en la costa, sierra y selva peruana, indicando que ésta bacteria esta ampliamente distribuida en los diferentes ecosistemas del país. De todas las áreas geográficas, la selva presenta mejores condiciones ecológicas y por lo tanto abundantes reservorios para la sobrevivencia de 
las Leptospiras (Liceras de Hidalgo. 1981). En la selva la Leptospira ha sido detectada en marsupiales, iguana, ardilla y conejo silvestre así como en bovinos. cerdos, caminos y humanos (Liceras de Hidalgo, 1981: Liceras de Hidalgo y Mejia, 1981) pero no hay información con respecto al Capibara.

Esta bacteria espirilada es eliminada en la orina del animal portador contaminando el pasto y el agua en donde la bacteria puede sobrev ivir por más tiempo. Los Capibaras permanecen gran parte del día en los ríos y ojos de agua por lo que el riesgo de infectarse con Leptopira es mayor. La presencia de anticuerpos con títulos de 1:100 a 1:400 contra 8 diferentes serovares de Leptospira en el $71.4 \%$ de las muestras, explica en parte este alto riesgo. El presente resultado es similar a lo reportado por investigadores del Centro de Investigaciones Veterinarias de Maracay. Venezuela quienes encontraron $63 \%$ de seroreactores (Jelambi, 1976).

A la fecha no se ha investigado el efecto patógeno de la leptospirosis en el Capibara, la ausencia de enfermedad clínica en estos animales durante el estudio de Jelambi (1976), sugiere que la infección por Leptospira en estos animales pueden ser de tipo subclínico y por tanto ser portadores de la bacteria constituy endo un serio riesgo para la salud pública.

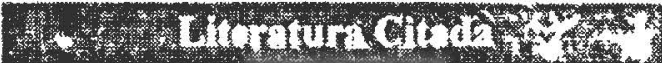

1. Bello, A. P.; P.M. Mogolloin; R. Villegas; Lasernay G Gómez 1974. La brucelosis en animales salvajes. El Chiguire. Vet Trop. 1: 117-128.

2. Castillo, O. 1986. Estructura primaria de la mioglobina del Chiguire. Acta Cientifica. Venezuelat 33 (Supl. 1). p36

3. Gonzúles-Jiméncz, E. 1995. El Capibara (Hydrochoerus hydrochaeras). Estado actual de su producción. FAO. Producción y Sanidad Animal. 122. $110 \mathrm{p}$.

4. Gonzales-Jiménez, E. 1990(1. Potencial of capibara production in Venezucla. Procceding II Inter. Wildlife Ranching Symposium Edmonton. Canada.

5. Jelambi, F. 1976. Leptospirosis en Chiguires. Informe del Centro de Investigaciones Veterinarias, CEXIP. FONAIAP, Maracay, Venezuela.

6. Liceras de Hidalgo, J. y' E. Mejia. 1981. Leptospirosis en Iquitos. Departamento de Loreto, Perú. Bol Otic Sanit Panam. 90 (2):152-158.

7. Liceras de Hidalgo, J. 1981. Leptospirosis en Tingo Maria, Departamento de Huánuco, Perú. II. Estudio en animales silvestres. Bol () Sanit Panam. 91(1): 47-54.

8. Morales, G 1978. El Capibara o C'higuiro como resen orio del Trypemosemarevemsi. Revista Colombiana de Ciencias Pecuariás. 1(2): 102.

9. Piccini, R.; W. Vale y F.W.R. Gómes. 1971. Criadouros artificiais de animalis silvestres. I criadouro de capibaras. Ministerio do Interior. Superintendencia do desenvolvimiento do Amazonia. Belen Departamento Recursos Naturais. Div. Documentacio. 